\title{
MULTINODULAR GOITER;
}

\author{
Frequency of malignancy
}

Dr. Zulfiqar Ali Bhatti, Dr. Javed Ahmed Phulpoto, Dr. Noor Ahmed Shaikh

ABSTRACT... Objective: The object of this study was to determine the frequency and type of thyroid carcinoma in Multi nodular goiter (MNG) after surgical resection on histopathological basis. Introduction: Multi nodular goiter (MNG) is one of the common presentations of various thyroid diseases. Thyroid nodules have been reported to be found in $4 \%$ to $7 \%$ of the population on neck palpation. Although in comparison to solitary nodule, the risk of malignancy in MNG is low but certain studies are showing significant risk. Material and methods: This prospective, observational study was carried out in the surgical unit I of Ghulam Mohammad Mahar Medical college hospital sukkur from 2007 to 2012. 94 cases with clinical diagnosis of MNG were analyzed during this period. All the patients were admitted through opd with routine investigations plus investigations specific to thyroid including thyroid profile, thyroid scan, FNAC of dominant nodule before being subjected to surgery. All FNACs were carried out at agha khan university hospital Karachi. Histopathology of operated specimen was the main criteria for malignancy. Results: Among the 94 cases which were included in this study, 9 (9.5\%) cases containing foci of malignancy. Incidence of malignancy commonly occurs in females, papillary carcinoma is being the commonest entity. Conclusions: The incidence of malignancy in MNG in this study is $9.5 \%$ that is quite high. So people should be educated and encouraged to attend the thyroid clinics for proper evaluation and early diagnosis of Malignancy.

Key words: Multinodular goiter, carcinoma, histopathology

Article Citation

Bhatti ZA, Phulpoto JA, Shaikh NA. Multinodular goiter; frequency of malignancy. Professional Med J 2013;20(6): 1035-1041.

\section{INTRODUCTION}

Enlargement of thyroid gland is a common problem. Its true incidence is unknown though it is endemic in the northern areas of Pakistan especially in Swat, Dir. and Chitral districts of Khyber Pakhtunkhwa and certain areas of Sindh province especially sukkur and ghotki . The most common cause of goiter formation is iodine deficiency. According to UNICEF (1998) report, 70\% of the total population in Pakistan is at risk of iodine deficiency disorder. Other causes include heredity, neoplasia, inflammations, drugs and exposure to radiations.

Thyroid cancer is uncommon, with an estimated incidence in various parts of the world as 0.5 to 10 cases per 100,000 populations. It accounts roughly for about $0.5 \%$ of all cancers in men and $1.5 \%$ of all cancers in women'. The most common types of thyroid cancers are differentiated, with papillary carcinoma $70 \%$, follicular carcinoma $12 \%$ and the follicular variant of the papillary carcinoma $6 \%$ of all the thyroid cancers ${ }^{2}$. It may present solitary nodule or as a dominant nodule in a multinodular goiter. In
Pakistan, thyroid cancer accounts for $1.2 \%$ cases of all malignant tumors ${ }^{3}$.

Multinodular goiter MNG is one of the common presentations of various thyroid diseases. Thyroid nodules have been reported to be founded in $4 \%$ to $7 \%$ of population on neck palpation and $30 \%$ to $50 \%$ population on ultrasonographyy ${ }^{4,5,6}$. MNG had been traditionally thought to be at low risk for malignancy as compared to solitary nodule of thyroid ${ }^{7.8}$. Various studies showing the incidence rate of carcinoma in MNG varies from $4 \%$ to $17 \%, 9,10,11,12,13$.

The management of solitary nodule of thyroid has been refined by FNAC, unlike MNG, in which nodule of carcinoma cannot be differentiated clinically and radiologically amidst other benign nodules ${ }^{14,15}$.

The objective of this study was to assess the incidence of malignancy in MNG in surgically resected specimens. 


\section{MATERIALS AND METHODS}

This prospective and observational study was carried out from January 2007-2012 in Surgical Unit I Ghulam Mohammad Mahar Medical College hospital, Sukkur. 94 patients with clinical diagnosis of MNG were analyzed. All these patients were admitted through OPD with all routine investigations plus investigation specific to thyroid including thyroid profile, thyroid scan, ultrasound neck, FNAC of dominant nodule before being subjected to surgery. All FNAC were carried out through agha khan university hospital Karachi. Histopathologies of operated specimen were the main criteria for malignancy. None of these patients had a history of irradiation of neck or family history of thyroid malignancy.

Most of patients were euthyroid in status. Patients with solitary thyroid nodule, recurrent goiter, proven thyroid malignancy and metastatic cervical lymphadenopathy with occult primary were excluded from this study.

All pre-operative, operative and postoperative findings were recorded in detail in standard format and the results were evaluated.

\section{RESULTS}

In this prospective study, 94 cases were included without any specific consideration to age, sex and ethnic groups. Out of 94 cases, $12(12.8 \%)$ were male and $82(87.2 \%)$ were female with $\mathrm{M}: \mathrm{F}$ ratio 1:6.8. Majority of patients presented with MNG between 3rd to 4th decades (Table I). Most of patients presented with the history of swelling in front of neck, while dyspnea and dysphagia were the next more significant complaints (Table II). 2 patients were supposed to have a malignancy on clinical grounds, which was later on proved on paraffin section (Table IV). In this study not a single of goiter with retrosternal extension was noted.

Out of 94 cases 2 were presented with signs of thyrotoxicosis and rest with euthyroid status. Not a single patient manifested any evidence of hypothyroidism (Tables III, VI).

\begin{tabular}{|l|c|c|c|}
\hline \multicolumn{1}{|c|}{ Age group } & No. of patients & Male & Female \\
\hline 11-20 years & 02 & 01 & 01 \\
\hline 21-30 years & 07 & 01 & 06 \\
\hline 31-40 years & 45 & 04 & 41 \\
\hline 41-50 years & 35 & 05 & 30 \\
\hline 51-60 years & 04 & - & 04 \\
\hline$>60$ & 01 & 01 & - \\
\hline Total & 94 & 12 & 82 \\
\hline
\end{tabular}

Table-I. Age distribution

\begin{tabular}{|l|c|c|}
\hline \multicolumn{1}{|c|}{ Complaints } & No. of Pts. & \%age \\
\hline Thyroid swelling & 94 & $100 \%$ \\
\hline Dyspnoea (on lying down) & 18 & $19.1 \%$ \\
\hline Dysphagia & 08 & $8.5 \%$ \\
\hline Pain in swelling & 02 & $2.1 \%$ \\
\hline Palpitation & 04 & $4.2 \%$ \\
\hline Features of thyrotoxicosis & 02 & $2.1 \%$ \\
\hline $\begin{array}{l}\text { Hoarseness of voice (unilateral } \\
\text { cord paralysis) }\end{array}$ & 02 & $2.1 \%$ \\
\hline
\end{tabular}

Table-Il. Presenting complaints

\begin{tabular}{|l|c|}
\hline Total no. of patients & 94 \\
\hline Euthyroid & $92(97.9 \%)$ \\
\hline Hyperthyroid & $2(2.1 \%)$ \\
\hline Hypothyroid & - \\
\hline
\end{tabular}

Table-III. Thyroid status on clinical assessment

\begin{tabular}{|c|c|c|}
\hline \multirow{2}{*}{$\begin{array}{c}\text { Total no. of } \\
\text { cases }\end{array}$} & \multicolumn{2}{|c|}{ Malignancy suspected clinically } \\
\cline { 2 - 3 } & Male & Female \\
\hline 94 & 01 & 01 \\
\hline
\end{tabular}

Table-IV. Clinical suspicion of malignancy 
On thyroid scanning 2 patients presented with hot nodule while rest were having cold nodule (Table V). Hormonal assay elicited 2 cases with hyperthyroidism and rest were euthyroid. (Table VI). All patients were subjected to FNAC from dominant nodule. Out of 94 cases, 7 were diagnosed having malignant goiter and rest were benign. (Table VII).

\begin{tabular}{|l|c|}
\hline Total No. of patients & 94 \\
\hline Euthyroid & 92 \\
\hline Hyperthyroidism & 02 \\
\hline Hypothyroidism & - \\
\hline \multicolumn{2}{|c|}{ Table-VI. Hormonal assessment } \\
\hline
\end{tabular}

\begin{tabular}{|l|c|}
\hline No. of patients & 94 \\
\hline Hot nodule & 02 \\
\hline Cold nodule & 92 \\
\hline Warm nodule & - \\
\hline
\end{tabular}

Table-V. Thyroid scanning

\begin{tabular}{|l|c|}
\hline Total No. of patients & 94 \\
\hline Benign & $87(92.5 \%)$ \\
\hline Malignant & $7(7.4 \%)$ \\
\hline \multicolumn{2}{|c|}{ Table-VII. FNAC based histopathological results } \\
\hline
\end{tabular}

\begin{tabular}{|l|c|c|c|c|}
\hline \multicolumn{1}{|c|}{ Type of malignancy } & No. of pts. & Age (years) & Male & Female \\
\hline Papillary carcinoma & $6(66.7 \%)$ & $30-50$ & 1 & 5 \\
\hline Follicular carcinoma & $2(22.2 \%)$ & $40-60$ & 1 & 1 \\
\hline Anaplastic carcinoma & $1(11.1 \%)$ & 72 & - & - \\
\hline Medullary carcinoma & - & - & - & - \\
\hline Others & - & - & $3(33.3 \%)$ & $6(66.8 \%)$ \\
\hline & $9 / 94(9.5 \%)$ & - &
\end{tabular}

FNAC accuracy rate was $77.8 \%$. On histopathological grounds, 9 cases were diagnosed having malignant goiter. Females are affected more commonly then males. Malignancy was noted more commonly in $3^{\text {rd }}$ to $4^{\text {th }}$ decade of life. In this study overall incidence of malignancy in MNG was $9.5 \%$ with M:F ratio 1:2. Papillary carcinoma is the most common variant. (Table VIII)

\section{DISCUSSION}

Multinodular goiter is defined as the palpation of multiple distinct nodules in the enlarged thyroid gland. The etiopathogenesis of MNG in not clear. The malignancy predominantly occurred in females, so hormonal influence may be considered to be the etiological factor for malignant changes in goiter. Majority of patients come from iodine deficient areas. Some patients presented with prolonged history of goiter. These are the etiological factors known to induce malignancy ${ }^{16}$. The presence of thyroid stimulating immunoglobulins have been suggested as the various causes ${ }^{14}$.

Thyroid nodules have been reported in $4 \%$ to $7 \%$ of the population on neck palpation (the incidence increases with age) and in $30 \%$ to $50 \%$ of the population by ultrasonography ${ }^{4,5,6}$. It has been observed that $50.5 \%$ of the solitary nodules which are felt on palpation are actually a part of the multi-nodular goiter ${ }^{4}$. The appreciation of the nodules may be hampered by the 
presence of a short and thick neck ${ }^{4}$. Even the experienced physicians may fail to detect the nodules when they are less than $1 \mathrm{~cm}$ in diameter ${ }^{4,17}$.

In MNG, surgery is offered for cosmetics, the compressive symptoms, toxicity and for the suspicion of malignancy. A long standing and hitherto unresolved issue is whether MNG is significantly associated with malignancy MNG had been traditionally thought to be at a low risk for malignancy as compared to a solitary nodule thyroid ${ }^{7,8,18}$. However, various studies have shown that the risk is quite high in MNG also. A study which was conducted by Benzarti et al in Tunis found a $9.5 \%$ incidence of malignancy in MNG ${ }^{19,20}$. Prades et al from France, however, reported quite a high incidence i.e. $12.2 \%^{19,21}$.

\section{FOREIGN LITERATURE}

1. The incidence of malignancy in MNG is $17 \%$.

2. The risk of malignancy is lower in MNG than in solitary nodule with reported malignancy rate between $4-10 \%^{22}$.

3. The frequency of carcinoma in MNG was $7.5 \%$ in patients older than 21 years and $11.5 \%$ under 21 years $^{23}$.

\section{LOCAL LITERATURE}

1. Study conducted at Chandka Medical College Larkana, showing the incidence of malignancy in MNG is $7.7 \%$.

2. Study conducted at liaquat Medical College Jamshoro showing the incidence of malignancy in MNG varies from 4-7\% ${ }^{24}$.

3. Incidence of malignancy in MNG was $11.9 \%$ in one of study conducted at Jinnah Post graduate Medical Centre, Karachi' ${ }^{13}$.

In our study ,the incidence of malignancy in MNG is $9.5 \%$, which is comparable to local and international studies. Out of 94 cases 82 were females and 12 were males with $M: F$ ratio was 1:6.8. There is predilection of MNG in females ${ }^{25}$. Majority of patients with MNG in our study were in the range between 30-53 years ,with maximum incidence in 3rd and 4th decade ${ }^{12}$. The maximum incidence of malignancy in this study was analyzed in age range of $30-50$ years which is comparable to literature ${ }^{26}$.

In this study, malignancy predominantly occurred in females, so hormonal influence may be considered to be the etiological factor for malignant changes in goiter. Majority of patients come from iodine deficient areas.

Two patients presented with thyrotoxicosis and rest were euthyroid. In two patients, malignancy was diagnosed on clinical grounds, which was confirmed later on histopathology. One patient with papillary carcinoma presented with secondaries in lung and parietal bones and other with anaplastic carcinoma. Both these cases presented with hoarseness of voices with unilateral cord paralysis. Rest of cases presented as occult carcinoma. FANC showed malignancy in 7 cases with accuracy rate of $77.7 \%$, which is comparable to literature ${ }^{27}$.

A thyroid nodule should be viewed with suspicion if it is seen as a dominant nodule in the MNG, which is hard, irregular, fixed and rapidly increasing, seen along with cervical lymphadenopathy, recurrent laryngeal nerve palsy, extremes of age and the male sex. A patient with a history of neck irradiation or a family history of thyroid carcinoma (TC) should make the suspicion strong ${ }^{19}$. High-frequency, real-time ultrasonography and fine-needle aspiration cytology (FNAC) are the indispensible tools which are used in the pre-operative evaluation of MNG for malignant foci. The important sonographic findings which are suggestive of malignancy in the thyroid nodules are micro-calcifications, irregular margins of the nodules, a complex echogenecity and smaller nodules ${ }^{4}$. It has been postulated that the thyroid cancers would have manifested with more overt signs and symptoms of local invasion or metastasis by the time they had 
reached significant size ${ }^{4}$. FNAC is a fast and inexpensive investigation which can be done to obtain cellular samples ${ }^{4}$. A series of reviews have reaffirmed its importance in the assessment of the thyroid nodules. However, a negative FNAC report does not exclude with certainty the possibility of a carcinoma, especially in MNG, where the error in sampling the right area is greater ${ }^{9,10}$. FNAC of a suspicious nodule under USG guidance $s$ of great help $p^{8,18}$. Thyroid carcinomas account for $1 \%$ of all the malignancies and they are the most common endocrine tumors ${ }^{19}$. The incidence of TC varies considerably in different regions of the world. Globally, the incidence of TC has increased by up to five-fold during the past 60 years ${ }^{7,28}$.

The tumors are rare in children and their frequency increases with age. Overall, females have a higher incidence of $\mathrm{TC}^{19}$. Ionizing radiation, iodine deficiency and other factors have been attributed for the increase in TC, but these findings are inconsistent ${ }^{7}$. Hormonal factors, lactation suppressant drugs and fertility medications have been implicated for the high incidence of TC in females ${ }^{19}$. However, recent studies have reported no significant risk associated with the use of hormone replacement therapy or fertility drugs $^{19,29,30}$. It also has been proposed that the availability of better and more sensitive diagnostic tools may detect early malignancy ${ }^{7,31}$.

Recent studies have suggested that the microcarcinomas classically progress to a clinically evident disease if they are left untreated ${ }^{31,32}$. The treatment of papillary micro-carcinoma should be similar to that of papillary thyroid cancer $^{30,31}$.

\section{CONCLUSIONS}

Incidence of malignancy in MNG is significantly high and commonly occurs in females, papillary carcinoma being the most common variant. Incidence of malignancy is more common in iodine deficient areas, particularly with prolonged history of goiter and huge goiter. So iodine deficiency seems to be one of the major factors inducing malignancy. This needs to be further evaluated. Females are more prone to have malignancy then males probably because of hormonal influence, this also needs further evaluation. Peoples should be educated and encouraged to attend the thyroid clinics for proper evaluation and early diagnosis.

\section{Copyright@C 20 Aug, 2013.}

\section{REFERENCES}

1. Sherman SI. Thyroid carcinoma. Lancet 2003;361:501-11.

2. Boigon M, Moyer D. Solitary thyroid nodules, separating benign from malignant conditions. Postgrad Med 1995;98:77-80.

3. Shah SH, Muzaffar S, Soomro I N. Morphological patterns and frequency of thyroid tumors. J Pak Med Assoc 1999;49:131-3.

4. Pang H-N, Chen C-M. The incidence of cancer in nodular goiters. Ann acad Med Singapore 2007; 36:241-43.

5. Belfiore A, La Rosa GL, Padova G, Sava L, Ippolito 0, Vigneri $R$. The frequency of cold thyroid nodules and malignancies in patients from an iodine deficient area. Cancer 1987;60:3096-102.

6. Mazzaferri EL, de los Santos ET, Rofagha-Keyhani S. Solitary thyroid nodule: diagnosis and management. Med Clin North Am 1988;72:1177-211.

7. Memon W, Khanzada TW, Samad A, Kumar B. Incidence of thyroid carcinoma in multinodular goiter. Rawal Med J 2010;35

8. Gandolfi PP, Frisina A, Raffa M, Renda F, Rocchetti 0 , -Ruggeri $C$,etal. The incidence of thyroid carcinoma in multi-nodular goitre: a retrospective analysis. Acta Bio Medica Ateneo Parmense 2004; 75:114-17.

9. Cole WH, slaughter DP, and Rossiter LI. Potential danger of non-toxic nodular goiter. J.A.M.A.1945; 127:883-888.

10. Cole WH. Incidence of carcinoma of the thyroid in 
nodular goitre. Semin Surg Oncol 1991;7(2):61-63.

11. Sachmechi I, Miller E, Varatharajah R, et al. Thyroid carcinoma in the single cold nodules and in the cold nodules of multi-nodular goitres. Endocr Pract 2000; 6(1): 110-112.

12. Shaikh Sikander Ali, Shaikh Sher Mohd, Burdi GM. Nodular goiter in : Jr of Coll. Of physician \& Surgeon of Pakistan 1992;2(4):93-94.

13. Soomro Salim, Shah Zaman, Nusrat Anis, Subhani Anis, Baloach Majeed. Incidence of carcinoma in nodular goiter. Journal of surgery Pakistan Vol.2(1): Jan 1997;6-7.

14. Abu-Eshy SA, Khan AR, Khan GM, Al-Humaidi MA, AlShehri MY, Malatani TS. Thyroid malignancy in multinodular goiter and in a solitary nodule. J. R. Coll. Surg. Edinb 1995;40:310-12.

15. Koh KB, Chang KW, Carcinoma in multinodular goiter. Br. J.Surg. 1992;79(3):266-67.

16. Shore RE. Issues and epidemiological evidence regarding radiation induced thyroid cancer. Radiat. Res.131:98-111,1992.

17. Tan GH, Gharib H, Reading CC. Solitary thyroid nodule. Comparison between palpation and ultrasonography. Arch Intern Med 1995; 155:2418-23.

18. Pedamallu R, Pedamallu SB, Rama Rao K, Pedamallu $\mathrm{CS}$. Incidence of occult carcinoma in multi-nodular goitre which was diagnosed on the basis of the histopathological findings. The Internet Journal of Surgery . 2008 Volume 17 Number 1.

19. Najum ul Haq R, Ali Khan B, Ahmed Chaudhry I. Prevalence of malignancy in goitre-a review of 718 thyroidectomies. J Ayub Med Coll Abbottabad 2009; 21(4).

20. Benzarti S, Miled I, Bassoumi T, Ben Mrad B, Akkari K, Bacha 0,et al. Thyroid surgery (356 cases): the risks and complications. Rev Laryngol Otol Rhinol (Board) 2002;123 (1):33-37.

21. Prades JM, Dumollard JM, Timoshenko A, Chelikh L, Michel F, EstourB, et al. Multi-nodular goitre: surgical management and histopathological findings. Eur Arch otolaryngol 2002; 259:2217-21.
22. Sheppard MC, Franklyn JA. Thyroid nodule and thyroid cancer. In: Oxford text book of medicine, 3rd edition.1996;vol.2:1618-1621.)

23. Pelizzo MR, Bernante $P$, Toniato A, Fassina A. Frequency of thyroid carcinoma in recent series of 539 consecutive thyroidectomies of MNG, Tumori 1997;May June :83(3):653-655.

24. Shaikh Zaman, Hussain Nasir, Bushra Anwar, Hassan Sajjid, Ali Zubair. Thyroid related disorders In: Jr. of college of Physicians \& Surgeons of pakistan1993;3(4):26-128.

25. Ermans Marie Andre. Disorders of iodine deficiency endemic goiter In: Werner C Sidney, Ingbar H, Sidney eds. The thyroid a fundamental and clinical text, Newyork. Harper and Row1978:537-49.

26. Sadler Gregory P, Clark Orlo H, Van HeerdenJoh A, Farley David R. Thyroid and parathyroid. In: Principle of surgery by Schwartz ed. Mc Graw-Hill Book CoSingapurvol, 2:1999;1661-1714.)

27. Davoudi MM, Yeh Ka, Wei JP. Utility of FNAC and frozen section examination in the operative management of thyroid nodules. AmSurg.1997;Dec;63(12):1084-90.

28. Whelan SL, Parkin DM, Masuyer E. The patterns of cancer in five continents. IARC sci publ 1990; 102:152-53.

29. Memon A, Darif M, Al Saleh K, Suresh A. Epidemiology of the reproductive and hormonal factors in thyroid cancer: evidence from a case control study in the Middle east. Int J Cancer 2002; 97:82-9.

30. La Vecchia C, Ron E, Franceschi S, Dal Maso L, Mark $\mathrm{SD}$, Chatenoud $\mathrm{L}$, et al. A pooled analysis of the casecontrol studies of thyroid cancer; Oral contraceptives, menopausal replacement therapy and other female hormones. Cancer causes Control 1999; 10:157-66.

31. Cerci C, Cerci SS, Eroglu E, Dede M, Kapucuoglu N, Yildiz M, et al. Thyroid cancer in toxic and non-toxic multi-nodular goitre. J Postgrad Med 2007; 53:15760.

32. Barbaro D, Simi U, Meucci G, Lapi P, Orsini P, Pasquini 
C. Thyroid papillary cancers: Micro-carcinoma and carcinoma, incidental cancers and non-incidental cancers - are they different diseases?.. Clin Endocrinol oxf 2005; 63:577-81.
33. Kucuk NO, Tari P, Tokmak E, Aras G. Treatment for micro-carcinoma of the thyroid-a clinical experience. Clin Nucl Med 2007; 32:279-8.

\section{AUTHOR(S):}

1. DR. ZULFIQAR ALI BHATTI, FCPS

Consultant Surgeon,

Ghulam Mohd Mahar Medical College (GMC) \& Hospital Sukkur.

2. DR. JAVED AHMED PHULPOTO, FCPS

Assistant Professor of Medicine,

Ghulam Mohd Mahar Medical College (GMC) \&

Hospital Sukkur.

3. Dr. NOOR AHMED SHAIKH, FCPS

Senior Registrar, Paeds Surgery,

Ghulam Mohd Mahar Medical College (GMC) \&

Hospital Sukkur.
Correspondence Address:

Dr. Zulfiqar Ali Bhatti, FCPS

Consultant Surgeon,

Ghulam Mohd Mahar Medical College (GMC) Hospital Sukkur drzulfiqarbhatti70@yahoo.com

\section{PREVIOUS RELATED STUDIES}

Syed Ali Akbar, Nazir Ahmed, Johar Ali, Mohammad Qasim, Zar Khan, Nazar Mohammad Afridi, MULTINODULAR GOITRE; FREQUENCY OF MALIGNANCY AND ITS HISTOPATHOLOGICAL TYPES. A TERTIARY CARE HOSPITAL EXPERIENCE (Original) Prof Med Jour 17(1) 40-43 Jan, Feb, Mar 2010.

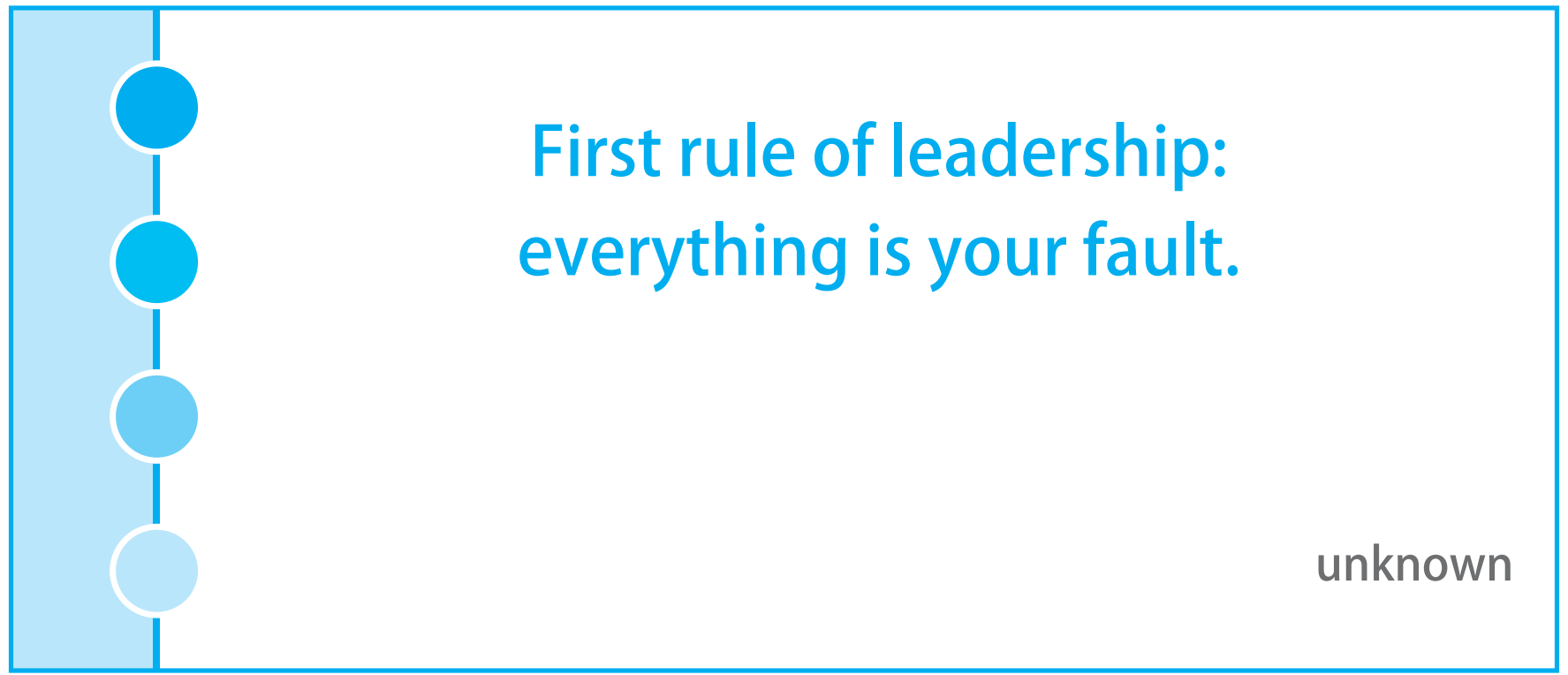

